И. О. Жаринов. Диверсификация компаний оборонно-промышленного комплекса в институциональных условиях цифровизации российской экономики

Научная статья

УДК 334

DOI 10.18101/2304-4446-2021-3-55-65

\title{
ДИВЕРСИФИКАЦИЯ КОМПАНИЙ ОБОРОННО-ПРОМЫШЛЕННОГО КОМПЛЕКСА В ИНСТИТУЦИОНАЛЬНЫХ УСЛОВИЯХ ЦИФРОВИЗАЦИИ РОССИЙСКОЙ ЭКОНОМИКИ
}

\section{(C) Жаринов Игорь Олегович}

доктор технических наук, профессор,

Национальный исследовательский университет ИТМО

Россия, 197101, г. Санкт-Петербург, Кронверкский пр., д. 49, лит. А mpbva@mail.ru

Аннотация. Рассматривается задача синтеза системы экономического управления для компании оборонно-промышленного комплекса Российской Федерации, деятельность которой диверсифицирована в направлении изготовления гражданской продукции. Диверсификация осуществляется с целью сохранения рыночных позиций компании в условиях цифровизации отечественной промышленности и сокращения объемов бюджетного финансирования. Диверсификация предполагает такой путь преобразования бизнес-процессов, в результате которого бизнес-проекты компании будут состоять из заказов, обеспеченных целевым образом государством, бизнес-партнерами и потребительским сообществом. Параллельное сопровождение разнородных заказов в пределах одной компании обусловливает трансформацию существующих бизнесмоделей компании и перевод системы экономического управления компанией на регулирование бизнес-процессов и бизнес-проектов, отличающихся как по способу финансового контроллинга, так и по требованиям к качеству производимой продукции. Определены факторы производства и нюансы, выступающие дифференцирующим признаком в разделении тематических заказов компании во внутренних бизнеспроцессах. Предлагается схема системы экономического управления, взаимозависимо регулирующей бизнес-процессы и бизнес-проекты компании, параллельно поддерживающей несколько отличающихся бизнес-моделей. Актуальными бизнес-моделями для диверсифицированной компании выступают модели: бизнес для бизнеса, бизнес для потребителя и бизнес для государства. Результаты исследования имеют теоретическое и практическое значение для компаний оборонно-промышленного комплекса, заинтересованных в сохранении и усилении своих рыночных позиций в институциональных условиях сокращения объемов государственного заказа и наблюдаемой сегодня цифровизации экономики.

Ключевые слова: диверсификация, компания, оборонно-промышленный комплекс, система экономического управления, бизнес-модель, регулирование, бизнеспроцессы, бизнес-проекты

\section{Для цитирования}

Жаринов И. О. Диверсификация компаний оборонно-промышленного комплекса в институциональных условиях цифровизации российской экономики // Вестник Бурятского государственного университета. Экономика и менеджмент. 2021. № 3. С. 55-65. 


\section{1 Введение}

В складывающихся в настоящее время инфраструктурных и институциональных условиях цифровизации российской экономики драйверами трансформации отечественного оборонно-промышленного комплекса (ОПК) оказываются средний и крупный бизнес, по своим ресурсным возможностям способный осуществить замену в компаниях изношенных основных производственных фондов поколения Индустрии 3.0 и организовать высокопроизводительные новые и модернизировать существующие рабочие места, претенденты на которые будут обладать специальными компетенциями в области цифровых технологий. Определяющими «рычагами» трансформации индустриального производства становятся не финансовые ресурсы государства и корпораций, линейно увеличенное вложение которых в бизнес-структуры ранее гарантировало получение отдачи в виде эквивалентного вклада бизнеса в национальный валовый внутренний продукт (ВВП), а технологии и инновационные результаты их применения, приложенные к развитию компаний ОПК, и их диверсификации в сегмент гражданского производства.

Диверсификация как общепризнанный сегодня и актуальный путь экстенсивного развития ОПК Российской Федерации, сформулированный премьерминистром РФ Д. А. Медведевым в 2016 г. в своей программной статье «Новая реальность: Россия и глобальные вызовы», имеет ряд особенностей, связанных с принятой в бизнес-структурах ОПК еще с советских времен системой экономического управления хозяйственной деятельностью, предполагающей целевое сопровождение одной бизнес-модели, сконцентрированной на обслуживании государственного заказа. В результате диверсификации деятельности ОПК в компаниях образуются несколько разных, но реализуемых параллельно бизнесмоделей, основанных на субмоделях извлечения дохода и субмоделях предложения продукции в системах экономических отношений: бизнес для бизнеса, бизнес для потребителя и бизнес для государства.

Поддержка в одной компании ОПК нескольких отличающихся бизнесмоделей является подходом к экономическому управлению хозяйствующим субъектом, согласующимся с идеями работы [1], предполагающими различные способы ресурсного воспроизводства потребительской ценности в системе рыночных отношений бизнес-партнеров. Производственные факторы компании в этом случае выступают разграничительными признаками, отражающими внутренние свойства хозяйствующего субъекта и влияющими на механизмы внутрифирменного регулирования бизнес-процессов и бизнес-проектов компании. Эффективность сочетания в пределах одной компании ОПК различных бизнесмоделей целесообразно оценивать индикативными показателями, основанными на существующих экономических категориях, в качестве которых в [2] рекомендуется, в частности, использовать приращение валовой прибыли или капитализацию активов компании.

Основная специфика создаваемой сегодня экономической модели развития промышленности РФ в целом и ОПК, в частности, сводится, по мнению авторов [3], к образованию в экономике новых конвергентно-технологических субъектов экономических отношений, в которых движение капиталов не будет требовать централизованного регулирования на государственном уровне или в преде- 
И. О. Жаринов. Диверсификация компаний оборонно-промышленного комплекса в институциональных условиях цифровизации российской экономики

лах хозяйственной деятельности корпораций. Базовыми хозяйствующими субъектами в цифровой модели экономики прогнозируются сетевые бизнесструктуры, отказывающиеся от принципов прямого государственного регулирования и использования экономических механизмов рыночного поглощения малого и среднего бизнеса в пользу создания бизнес-альянсов и региональных бизнескластеров, функционирующих на принципах самофинансирования и самоокупаемости и эффективно реализующих потенциал всех факторов высокотехнологичного производства компаний-партнеров.

\section{2 Комплементарные бизнес-процессы диверсификации ОПК}

Механизмы государственного регулирования деятельности ОПК, подробно рассмотренные в работе [4] в качестве допустимых мер прямого влияния на диверсифицируемый бизнес ОПК, сегодня задействуют:

- квотирование объемов производимой продукции, внешнеторговой деятельности и загрузку оборудования государственным заказом;

- лимитирование тарифных значений в структуре цены на конечную продукцию, введение законодательных требований по лицензированию продукции и ее сертификации;

- субсидирование и предоставление налоговых преференций на реализацию отдельных бизнес-проектов и льготное кредитование компаний с государственными обеспечительными гарантиями;

- инвестирование в обновление (модернизацию и импортозамещение) производственных мощностей компании ресурсами федеральных целевых государственных программ;

- пресечение практики недобросовестной рыночной конкуренции, проявляющееся в нарушении антимонопольного законодательства;

- создание системы организационного взаимодействия компаний в электронной информационной среде промышленности;

- введение ограничений и контроля в систему оплаты труда работников компаний и систему менеджмента качества продукции и др.

При трансформировании текущих бизнес-моделей компаний ОПК Индустрии 3.0 и их систем экономического управления под институциональные и инфраструктурные условия цифровизации и концепты Индустрии 4.0, согласно исследованию [5], необходимо учитывать производственные факторы, представленные, в частности, в таблице 1 и подлежащие интеграции.

В результате диверсификации операционной деятельности ОПК ожидается рыночная реализация компаниями параллельно нескольких бизнес-моделей взаимодействия производителя и потребителя продукции, в которых сохранится доминирующее положение бизнес-процессов, формирующих основную прибыль в цепочке стоимости, и сопутствующее положение бизнес-процессов, вносящих второстепенный вклад в добавленную стоимость продукции, в динамике хозяйственного субъекта, рассматриваемого как целостная экономическая система. Значимыми свойствами бизнес-моделей диверсифицированного ОПК, таким образом, являются: вид продукции или услуги и способы ее создания и вывода на рынок, влияющие на бизнес-поведение компаний. 
Особенности реализации текущих и диверсифицированных бизнес-процессов в российских компаниях ОПК

\begin{tabular}{|c|c|c|}
\hline $\begin{array}{c}\text { Производственный } \\
\text { фактор компании }\end{array}$ & $\begin{array}{c}\text { Продукция основного } \\
\text { профиля компании } \\
\end{array}$ & $\begin{array}{c}\text { Диверсифицированная } \\
\text { продукция компании }\end{array}$ \\
\hline $\begin{array}{c}\text { Номенклатура продук- } \\
\text { ции }\end{array}$ & $\begin{array}{c}\text { Формируется на основе } \\
\text { структуры гособоронзаказа }\end{array}$ & $\begin{array}{c}\text { Формируется в соответствии } \\
\text { с ожиданиями рынка }\end{array}$ \\
\hline $\begin{array}{c}\text { Продолжительность } \\
\text { жизненного цикла } \\
\text { продукции } \\
\end{array}$ & $\begin{array}{c}\text { В течение назначенного } \\
\text { ресурсного срока (до } 25 \text { лет) }\end{array}$ & $\begin{array}{l}\text { В течение коммерчески эф- } \\
\text { фективного срока (до } 7 \text { лет) }\end{array}$ \\
\hline $\begin{array}{c}\text { Способ финансирова- } \\
\text { ния производства и } \\
\text { НИОКР }\end{array}$ & $\begin{array}{c}\text { Государственное (бюджетное) } \\
\text { финансирование }\end{array}$ & $\begin{array}{c}\text { Финансирование из соб- } \\
\text { ственных средств или средств } \\
\text { инвесторов }\end{array}$ \\
\hline $\begin{array}{c}\text { Условия рыночной } \\
\text { конкуренции }\end{array}$ & $\begin{array}{c}\text { Конкуренция между компани- } \\
\text { ями внутри госкорпорации }\end{array}$ & $\begin{array}{c}\text { Конкуренция между компа- } \\
\text { ниями внутреннего и внешне- } \\
\text { го рынков }\end{array}$ \\
\hline $\begin{array}{c}\text { Специфика стратегии } \\
\text { экономического } \\
\text { управления } \\
\end{array}$ & $\begin{array}{c}\text { Соответствует планам и эко- } \\
\text { номической политике госкор- } \\
\text { порации } \\
\end{array}$ & $\begin{array}{c}\text { Соответствует динамике по- } \\
\text { требительской активности и } \\
\text { вызовам } \\
\end{array}$ \\
\hline $\begin{array}{c}\text { Нормативная процесс- } \\
\text { но-проектная доку- } \\
\text { ментация }\end{array}$ & $\begin{array}{c}\text { Государственные и отраслевые } \\
\text { стандарты группы РВ }\end{array}$ & $\begin{array}{c}\text { Государственные и отрасле- } \\
\text { вые стандарты группы P }\end{array}$ \\
\hline $\begin{array}{c}\text { Ограничения на ре- } \\
\text { сурсное обеспечение } \\
\text { проектов }\end{array}$ & $\begin{array}{c}\text { Отечественные и импортоза- } \\
\text { мещающие технологии }\end{array}$ & $\begin{array}{c}\text { Применяются наилучшие } \\
\text { производственные COTS- } \\
\text { технологии }\end{array}$ \\
\hline $\begin{array}{c}\text { Ограничения на «про- } \\
\text { зрачность» деятельно- } \\
\text { сти }\end{array}$ & $\begin{array}{l}\text { Закрытая отчетность, регули- } \\
\text { руемая уровнем безопасности }\end{array}$ & $\begin{array}{c}\text { Открытая для рынка (инве- } \\
\text { сторов и потребителей) фи- } \\
\text { нансовая отчетность }\end{array}$ \\
\hline
\end{tabular}

COTS - Commercial Off-The-Shelf

Экономические эффекты диверсификации ОПК связаны с возникновением новых типов звеньев в «гражданских» цепочках стоимости, основанных на анализе контента потребительского опыта и относящихся к бизнес-процессам создания кастомизированной смарт-продукции, бизнес-процессам удовлетворения индивидуализированного спроса и др., имеющим пониженные производственные издержки. Новые звенья в цепочках стоимости имеют киберфизическую природу и сочетают в себе комплементарные бизнес-процессы компаний ОПК, осуществляемые в реальной (физической) и виртуальной (облачной) производственной среде.

\section{3 Бизнес-кейсы диверсификации отечественных компаний ОПК}

Примером диверсификации крупной промышленной компании ОПК является кейс АО «Вертолеты России», внедрившего в свои операционные циклы проектно-производственной деятельности цифровые технологии. По данным государственной корпорации «Ростех», 2017 г., компания с использованием автоматизированных средств имитационного (виртуального) моделирования, электронного планирования и дистанционного мониторинга реализовала пилотный высокотех- 
И. О. Жаринов. Диверсификация компаний оборонно-промышленного комплекса в институциональных условиях цифровизации российской экономики

нологичный проект гражданского вертолета Ка-226Т. В сегменте отечественного гражданского самолетостроения интенсификация передовых производственных технологий на современном этапе концентрируется в реализации высокотехнологичных проектов создания и воспроизводства региональных объектов SSJ-100, ближне- и среднемагистральных самолетов MC-21, дальнемагистрального самолета CR-929 и др. Успешные кейсы цифровизации авиационной промышленности демонстрируют АО «Пермский моторный завод «Сатурн», АО «Климов», АО «ОДК - Авиадвигатель» и др.

Согласно отчетным данным круглого стола «Финансовая поддержка диверсификации предприятий ОПК в рамках реализации нацпроектов», 2021 г., текущие объемы выпуска гражданской продукции компаниями государственной корпорации «Ростех» составляют 31\% (550 млрд р.) от общего объема производимой продукции и прогнозируется дальнейший рост гражданского сегмента с целевым ориентиром не менее $50 \%$, ожидаемым к достижению в 2030 г. Поступательное наращивание доли гражданской продукции в ОПК является элементом государственной политики (в том числе планирования) и осуществляется с целью поддержания финансовой устойчивости бизнес-структур на внутреннем и внешних рынках в условиях институциональных и инфраструктурных преобразований промышленности и сохранения кадрового, производственного, технологического и других потенциалов компаний.

Материалы исследований [6], выполненные в предметной области диверсификации отечественных компаний ОПК, в свою очередь определяют в текущем моменте 50\%-ную долю оборота гражданской продукции ОПК, приходящуюся на три крупных бизнес-структуры: АО «Концерн ВКО «Алмаз-Антей», НПО «Высокоточные комплексы» и АО «КРЭТ». Еще $25 \%$ доли рынка гражданской продукции ОПК занимают примерно 680 компаний, вовлеченных в изготовление продукции промежуточного цикла в цепочках создания ценностей. Суммарно доля гражданской продукции ОПК в 2020 г. оценочно составила 26,3\% общего объема совокупного рынка гражданской продукции Российской Федерации, что соответствует 19,4\% национального ВВП. Сравнительные значения доли гражданской продукции ОПК в США в 2017 г. составили 64,5\%, а в Китае в 2016 г. 48,3\% общего объема производимой ОПК продукции.

Такие межнациональные расхождения показателей диверсификации (в разы) объясняются существенными отличиями стран в параметрах бюджетного финансирования ОПК (в РФ доля заказов, обеспеченных государственным бюджетом, доходит до 85-90\% портфеля заказов компаний, в то время как в США и Китае аналогичные значения находятся на уровнях примерно 40 и $30 \%$ соответственно, что стимулирует менеджмент зарубежных компаний к поиску новых точек роста прибыли в сегментах гражданской продукции). Для изменения баланса продуктовой линейки компаний ОПК и с целью поддержания диверсификации ОПК в целом в РФ на государственном уровне выделены и финансово поддержаны пять бизнес-структур: ПАО «Объединенная авиастроительная корпорация», АО «Объединенная двигателестроительная корпорация», АО «Объединенная судостроительная корпорация», АО «Вертолеты России» и АО «Концерн ВКО “Алмаз-Антей”», технологические и бизнес-компетенции которых потенциально способны создать и вывести в гражданской оборот высокотехнологичную продукцию. 
Поддержка моделей отношений «бизнес для бизнеса» и «бизнес для покупателя» поставлена во главу угла передовых программ диверсификации продуктовой линейки АО «Концерн ВКО “Алмаз-Антей”», входящего в ТОП-10 бизнесструктур ОПК по производству высокотехнологичной продукции и по основному профилю деятельности использующего базовую модель отношений «бизнес для государства». Согласно открытым данным концерна, опубликованным на его официальном сайте в сети Интернет, целевые ориентиры доли гражданской продукции, отталкивающиеся в 2020 г. от $17 \%$, к 2025 г. должны составить 30\%, а к 2030 г. - 50\% общего объема производимой продукции.

Основной недостаток существующего подхода к диверсификации ОПК Российской Федерации, отмеченный в частности в [7], заключается в изолированной трансформации бизнес-процессов и разработке нестандартизованных технологических решений каждой из компаний для изменения своих внутренних производственных циклов, что подтверждается наблюдаемой сегодня практикой в бизнесструктурах государственных корпораций «Росатом», «Ростех», «Роскосмос» и др.

\section{4 Бизнес-кейсы диверсификации зарубежных компаний ОПК}

Зарубежные авиационные компании, кейсы которых проанализированы в работе [8], так же активно осуществляют цифровизацию и диверсификацию своей проектно-производственной деятельности, обеспечивающей им долю мирового рынка самолетостроения в объемах: Boeing - 42,2\%, Airbus - 40,6\%, Embraer - 5,8\%, Bombardier - 4,2\%. Согласно оценочным данным [9], в поддержку своих передовых бизнес-моделей и производственных циклов ведущие авиационные компании осуществляют инвестиции в науку и высокотехнологичные разработки в следующих объемах от собственной валовой выручки: Boeing - 3,6\%, Airbus - 5,7\%, Embraer - 5,5\%. Аналогичный показатель, например, для отечественных ПАО «Объединенная авиастроительная корпорация» и АО «Вертолеты России» составляет соответственно 1,4 и 1,2\%, что уступает в разы объемам вложений зарубежных компаний в развитие бизнеса.

В ЕС «локомотивом» цифровизации и диверсификации промышленности выделены целые отрасли экономики (в Германии, в частности, обрабатывающее машиностроение), максимальная отдача от институциональных и инфраструктурных преобразований в которых (с неизбежными структурными диспропорциями экономического развития отдельных отраслей) ожидается в обозримой перспективе. Исследования [10] со ссылкой на отчет Honeyweel, свидетельствуют о готовности 47\% международных авиаперевозчиков в ближайший год вкладывать средства в цифровизацию собственных производственных циклов в размере до 500 тыс. долл., приходящихся на одно воздушное судно. По данным работы [11], опирающейся на результаты исследования New Vantage Partnets, выполненные в 2019 г. методом анкетирования представителей крупных промышленных корпораций, работающих в том числе на ОПК (General Electric, General Motors, Ford и др.), до 55\% компаний из опрошенных 64 осуществляли вложения в развитие собственного бизнеса в части автоматизации производственных мощностей и в части внедрения технологий искусственного интеллекта. Суммарный объем вложений за 2019 г. составил более 50 млн долл., что превышает аналогичный показатель 2018 г. на 40\%. 
И. О. Жаринов. Диверсификация компаний оборонно-промышленного комплекса в институциональных условиях цифровизации российской экономики

Цепочки ценности, проанализированные в работе [8], в авиационной промышленности образуются в результате цифровизации и диверсификации производительных бизнес-процессов и агрегирования продукции поставщиков различных уровней, к которым, в частности, относятся: Spirit Aero Systems, Aerospace Sealants, Zodiac Aerospace, GKN Aerospace и др. «Промежуточная» продукция (авиационные приборы и материалы), изготовленная с использованием цифровых технологий и распределенная в результате смарт-логистики, является гражданской составной частью основной операционной деятельности компаний: General Electric Aircraft, Pratt\&Whitney, SNECMA и др.

\section{5 Государственно-частное партнерство в финансировании проектов диверсификации ОПК}

По данным доклада НИУ Высшая школа экономики, 2019 г., внедрение сквозных цифровых технологий в компании потенциально может привести к повышению производительности труда персонала на 40\%. В свою очередь, результаты исследования [11], ссылающегося на McKinsey Global Institute, прогнозируют полную автоматизацию до 50\% рабочих мест к 2036 г. Повышение заинтересованности работодателей в расширенных компетенциях персонала нашло свое отражение в обновленных корпоративных стратегиях развития компаний ОПК Boeing, Lockheed Martin, Ford Motors, General Motors и др.

Отечественные показатели в структуре текущей занятости трудоспособного населения, проанализированные в работе [12], оцениваются в 2,5 млн человек, осуществляющих профессиональную деятельность в компаниях ОПК - «сердца» экономики РФ, - дополнительно обеспечивающего в смежных гражданских отраслях промышленности до 7,5 млн рабочих мест. Высокотехнологичная промышленность РФ в структуре ОПК наиболее представлена авиационным $(14,3 \%)$, ракетно-космическим (6\%), судостроительным $(9,5 \%)$, радиоэлектронным $(19,8 \%)$, коммуникационным $(7,5 \%)$ и другими сегментами, охватывающими более 1300 российских компаний, распределенных, согласно исследованию [5], между ГК «Ростех» (80\%), ГК «Роскосмос» (6\%), ГК «Росатом» $(3 \%)$ и др. Состав компаний ОПК регулируется Постановлением Правительства РФ от 20 февраля 2004 г. № 96 «О сводном реестре организаций обороннопромышленного комплекса» и приказом Министерства промышленности и торговли Российской Федерации от 3 июля 2015 г. № 1828 «Об утверждении перечня организаций, включенных в сводный реестр организаций обороннопромышленного комплекса».

Ретроспективный опыт стран Евросоюза в части оценки финансового участия государственно-частного партнерства в реализации интеллектуальных НИОКР как в ОПК, так и в других отраслях экономики, проанализирован в исследовании [13], согласно которому в период 2008-2018 гг. суммарная доля расходов государств ЕС в наукоемких разработках варьировалась в диапазоне от 35,2 до 29,6\%, в то время как негосударственные вложения бизнеса составляли $55,2-59,1 \%$ общего объема финансирования. Аналогичный показатель США за тот же период: 58-63\% - частный капитал, 32-23\% - государственное финансирование проектов НИОКР. Оценки внутренних вложений РФ в НИОКР составляют: 65-70\% доля государственных вложений и $27-30 \%$ - вклад частного бизнеса от общего объема финансирования. 
Сравнение указанных показателей свидетельствует о диаметрально противоположных позициях РФ и стран Запада в подходах к проектному финансирования ОПК. В таких условиях диверсификация, предполагающая сокращение объемов государственного заказа и привлечение частных инвестиций в гражданские бизнес-проекты, является хоть и «болезненным», но необходимым способом реформирования ОПК на современном этапе, который, помимо изменения продуктовой линейки, потребует также и создания новых комплементарных бизнесмоделей и систем экономического управления, регулирующих хозяйственную деятельность обновленных компаний ОПК. Схема системы управления, реализующей в пределах одной компании ОПК регулирование бизнес-проектов одновременно по нескольким бизнес-моделям, приведена на рисунке 1.

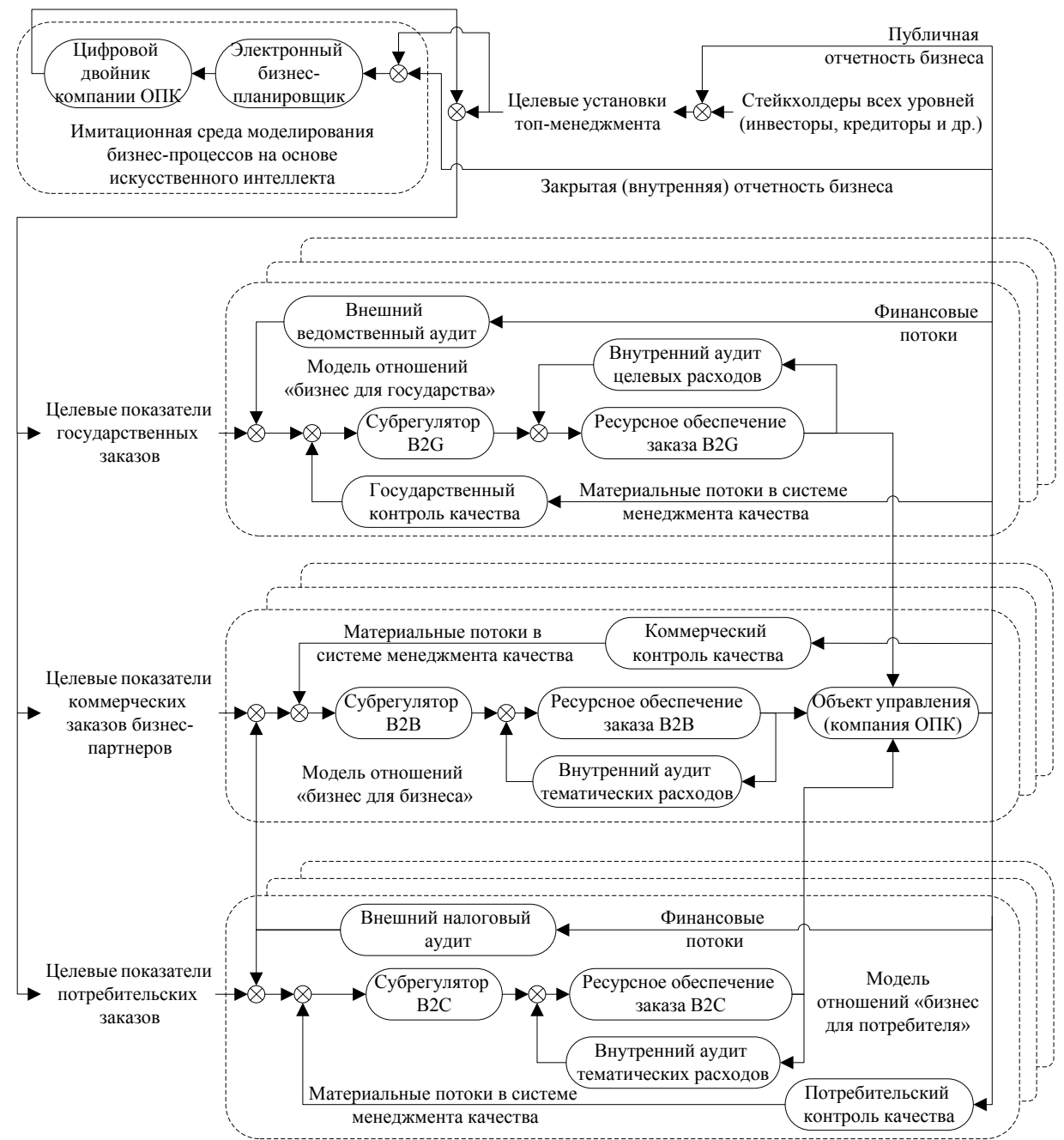

Рис. 1. Схема системы экономического управления, реализующей в пределах одной компании ОПК регулирование бизнес-проектов одновременно по нескольким бизнес-моделям (В2B - business-to-business, B2G — business-to-government, B2C — business-to-consumer) 
И. О. Жаринов. Диверсификация компаний оборонно-промышленного комплекса в институциональных условиях цифровизации российской экономики

\section{6 Заключение}

По данным работы [14], современные компании при трансформации собственных бизнес-процессов уделяют первоочередное внимание преобразованиям технологического компонента производства, следующим этапом во внедрении инноваций выступает организационный компонент структуры, обновлению маркетингового компонента, на который приходится до $10 \%$ инвестиций, отводится последнее место. В то время как именно маркетинг в условиях цифровизации экономики и изменений в бизнес-моделях взаимодействия компаний ОПК с потребительским сообществом является видом деятельности, развитие которого потенциально способно само по себе существенно увеличить выручку компаний и снизить издержки, образованные «пролеживанием» готовой гражданской продукции.

Вовлечение потребительского сообщества в заказы компаний ОПК и сопровождение процессов изготовления и дистрибуции продукции соответствуют передовым формам экономических отношений участников рынка, для регулирования которых сегодня вводятся стандарты нового поколения, в частности стандарт CSRP (Customer Synchronized Resource Planning). В отличие от широко применяемых сегодня в компаниях ОПК Индустрии 3.0 стандартов и электронных систем планирования и управления, например, ERP (Enterprise Resource Planning)-, MES (Manufacturing Execution System)- и MRP (Material Requirements Planning)-систем, ориентированных на регулирование внутренних бизнес-процессов компаний, стандарт CSRP подготовлен для поддержки полного жизненного цикла продукции во внутренних и внешних бизнес-процессах компании, в которых конечный «гражданский потребитель» может принимать долгосрочное участие в качестве заказчика и соразработчика (соизготовителя) продукции.

Такая схема взаимодействия производителя и потребителя составляет суть идеи клиентоцентричности гражданского рынка ОПК и поддерживается бизнесмоделями шеринговой экономики, востребованными в бизнес-процессах кастомизации продукции. По существу, бизнес-проекты компании ОПК, в том числе и осуществляющей массовый выпуск продукции, под давлением рынка (интересов покупателей) в результате диверсификации адаптируются (индивидуализируются) под требования заказчика, вследствие чего происходит перенастройка ряда внутренних бизнес-процессов компании, а самого потребителя можно рассматривать в качестве соуправляющего высокотехнологичной компанией и конечного выгодоприобретателя от реформирования ОПК.

\section{Лuтература}

1. Cachon G. P. A research framework for business models: what is common among fast fashion, e-tailing, and ride sharing? // Management science. 2019. Art. 3275. P. 1-21.

2. Сергиевич Т. В. Влияние цифровизации экономики и общества на трансформацию бизнес-моделей промышленных предприятий // Технико-технологические проблемы сервиса. 2021. № 2(56). С. 95-101. Текст: непосредственный.

3. Блокчейн как технологическая платформа сетевого типа структурогенезиса в экономике / С. А. Жиронкин, М. А. Гасанов, В. В. Гузырь, В. С. Жиронкин // Вестник Томского государственного университета. Экономика. 2020. № 49. С. 259-275. Текст: непосредственный.

4. Логиновский О. В., Халдин А. С., Шинкарев А. А. Влияние органов государственной власти субъектов РФ на развитие промышленных предприятий и корпораций // 


\section{ВЕСТНИК БУРЯТСКОГО ГОСУДАРСТВЕННОГО УНИВЕРСИТЕТА ЭКОНОМИКА И МЕНЕДЖМЕНТ}

Вестник Южно-Уральского государственного университета. Серия «Компьютерные технологии, управление, радиоэлектроника». 2020. Т. 20, № 4. С. 135-143. Текст: непосредственный.

5. Пронин А. Ю. Диверсификация оборонно-промышленного комплекса - инновационный путь развития экономики России // Экономика и бизнес: теория и практика. 2020. Т. 11, № 3(69). С. 10-14. Текст: непосредственный.

6. Ештокин С. В. Диффузия высоких технологий оборонно-промышленного комплекса в гражданский сектор экономики: стратегические шаги к импортозамещению // Вопросы инновационной экономики. 2021. Т. 11, № 1. С. 257-278. Текст: непосредственный.

7. Никулина О. В. Анализ влияния цифровизации мировой экономики на развитие инновационной деятельности промышленных предприятий // Экономика: теория и практика. 2020. № 1(57). С. 40-49. Текст: непосредственный.

8. Дементьев В. Е., Устюжанина Е. В., Евсюков С. Г. Цифровая трансформация цепочек создания ценности: «улыбка» может оказаться «хмурой» // Журнал институциональных исследований. 2018. Т. 10, № 4. С. 58-77. Текст: непосредственный.

9. Заступов А. В. Инновационное развитие предприятий промышленных отраслей в условиях цифровой модернизации экономики // Бизнес. Образование. Право. 2020. № 1(50). С. 244-250. Текст: непосредственный.

10. Михайлова Л. В., Сазонова М. В., Дикова О. Д. Особенности бизнес-модели и проблемы реализации новой технологической концепции в России // Вестник Московского государственного областного университета. Серия: Экономика. 2020. № 1. С. 66-73. Текст: непосредственный.

11. Боев А. Г. Содержание и особенности процесса институциональных преобразований промышленных комплексов в условиях цифровой экономики // Экономика в промышленности. 2020. Т.13, № 1. С. 18-28. Текст: непосредственный.

12. Абрамов С. А., Добровольский В. С., Добровольский Л. В. Современный состав оборонно-промышленного комплекса Российской Федерации и основные показатели его функционирования в 2017-2019 гг. // Автомобиль. Дорога. Инфраструктура. 2020. № 3(25). 26 с. Текст: непосредственный.

13. Руднева К. С. Модернизация промышленного сектора экономики: ключевые характеристики, подходы и этапы // Вектор экономики. 2020. № 3(57). С. 46-46. Текст: непосредственный.

14. Погодина Т. В., Удальцова Н. Л. Стратегическое управление конкурентоспособностью промышленных компаний в нестабильных рыночных условиях // Вестник Удмуртского университета. Сер. Экономика и право. 2020. Т. 30, № 1. С. 41-50. Текст: непосредственный.

Статья поступила в редакциию 25.07.2021; одобрена после рецензирования 30.07.2021; принята к публикации 18.08.2021. 
И. О. Жаринов. Диверсификация компаний оборонно-промышленного комплекса в институциональных условиях цифровизации российской экономики

\title{
DIVERSIFICATION OF DEFENSE INDUSTRY COMPANIES IN THE INSTITUTIONAL CONTEXT OF RUSSIAN ECONOMY DIGITALIZATION
}

\author{
Igor O. Zharinov \\ Dr. Sci. (Engineering), Prof., \\ ITMO National Research University, \\ 49a Kronverksky Prospect, St. Petersburg 197101, Russia \\ mpbva@mail.ru
}

Abstract. The article deals with the problem of synthesis of an economic management system for the Russian defense industry company, which activity is diversified in manufacturing civilian products. Diversification is carried out in order to maintain the company's market position in the context of domestic industry digitalization and to reduce the volume of budget funding. Diversification presupposes such a way of transforming business processes, as a result of which the company's business projects will include the orders secured in a targeted manner by the state, business partners and the consumer community. Parallel support of dissimilar orders within one company leads to the transformation of the company's business models and the transfer of the company's economic management system to regulation of business processes and business projects that differ both in the method of financial controlling and in requirements for the quality of products. In the article we have determined the differentiating factors of production and nuances in the division of thematic orders of a company in internal business processes. A diagram of an economic management system is proposed that interdependently regulates business processes and business projects of a company, and simultaneously support several different business models. The actual business models for a diversified company are business-to-business, business-to-consumer, and business-to-government models. The results of the study are of theoretical and practical importance for defense industry companies, aiming at maintaining and strengthening their market positions in the institutional context of reducing the volume of government orders and digitalization of the economy observed today.

Keywords: diversification, company, defense industry, economic management system, business model, regulation, business processes, business projects

\section{For citation}

Zharinov I. O. Diversification of Defense Industry Companies in the Institutional Context of Russian Economy Digitalization. Bulletin of Buryat State University. Economy and Management. 2021; 3: 55-65 (In Russ.).

The article was submitted 25.07.2021; approved after reviewing 30.07.2021; accepted for publication 18.08.2021. 